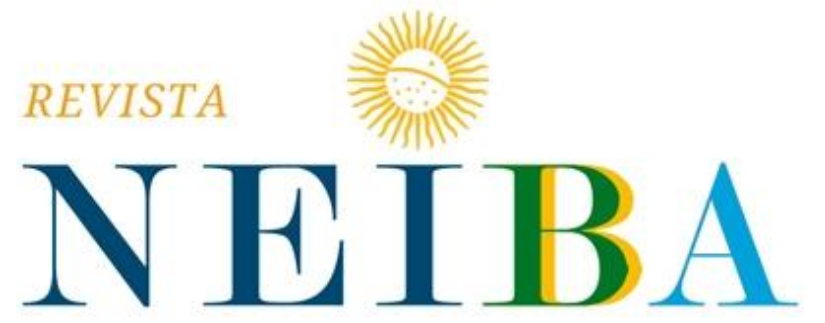

CADERNOS ARGENTINA-BRASIL
Volume 9,2020 , p. $01-20$

DOI: $10.12957 /$ neiba.2020.48425 | e48425 I ISSN: 2317-3459

\title{
VÍNCULOS COMERCIAIS DO ARQUIPÉLAGO MALVINAS E SUAS REPERCUSSÕES NOS PAÍSES DA AMÉRICA LATINA
}

LAZOS COMERCIALES DEL ARCHIPIÉLAGO MALVINAS Y SUS REPERCUSIONES EN LOS PAÍSES DE LATINOAMÉRICA

\section{Rogerio do Nascimento Carvalho ${ }^{1}$}

${ }^{1}$ Universidade de São Paulo (USP), São Paulo, SP, Brasil. E-mail: rogertheone@gmail.com ORCID: https://orcid.org/0000-0001-8598-6478

Recebido em: 12/02/2020 | Aceito em: 23/06/2020. 


\section{RESUMO}

Os vínculos comerciais de uma região demonstram a forma como se relacionam no mundo globalizado. O objetivo deste trabalho foi atestar a dificuldade de comércio do arquipélago Malvinas com os países da América Latina. Analisa-se conjuntamente o documento oficial do governo do arquipélago que atesta a dependência da estrutura de integração com o Reino Unido. A política britânica configura-se em obstáculo para integração econômica do arquipélago com demais países da América Latina visto que garante ao Reino Unido acesso privilegiado às riquezas geoeconômicas e estratégicas da região, mas com o evento do Brexit abrem-se oportunidades que elevam a discussão da situação do arquipélago no Atlântico Sul. A análise de dados permite afirmar que as relações diminutas de comércio com países da América Latina dificultam processos de aproximação e, por isso, é necessário reflexões sobre as alternativas a serem construídas pelos efeitos do Brexit para o deslinde da questão.

Palavras-chave: Malvinas, Integração, Economia.

\section{RESUMEN}

Los lazos comerciales de una región demuestran cómo se relacionan entre sí y con el mundo globalizado. El objetivo de este trabajo fue demonstrar la dificultad del comercio entre el archipiélago de Malvinas y los países de Latinoamérica. El documento oficial del gobierno del archipiélago atestigua la dependencia de la estructura con el Reino Unido. La política británica es un obstáculo para la integración económica del archipiélago con otros países latinoamericanos, ya que garantiza al Reino Unido el acceso privilegiado a la riqueza geoeconómica y estratégica de la región, pero con el evento Brexit hay miradas que aumentan la discusión acerca de la situación del archipiélago en el Atlántico Sur. El análisis de datos concluye que las relaciones comerciales disminuidas con los países latinoamericanos dificultan los procesos de aproximación y, por lo tanto, las reflexiones sobre las alternativas a obtener por los efectos del Brexit para la solución final de la cuestión.

Palabras-claves: Malvinas, Integración, Economía. 


\section{INTRODUÇÃO}

O arquipélago Malvinas, localizado no Atlântico Sul é pertencente ao continente americano e objeto de disputa entre Argentina e Reino Unido. A motivação pelo controle sobre o território já foi motivo de conflito armado em 1982, vencida pelos britânicos. Importante ressaltar que a área em questão foi invadida pelos britânicos em 1833 e, desde esta época, mantém sua soberania, à exceção do período compreendido entre 02 de abril a 14 de junho de 1982 em que a Argentina exerceu o controle do conjunto de ilhas. Pastorino (2013) aduz que a presença do Reino Unido no arquipélago é ilegítima e não reconhecida pela Argentina.

O objetivo geral do presente artigo é o de interpretar, dentro da vertente econômica a posição do arquipélago Malvinas e de suas relações comerciais segundo dados sistematizados pela Comissão Econômica para América Latina (CEPAL) e, tem como objetivos específicos: 1) Demonstrar a ausência de parcerias com países latinoamericanos; 2) Apontar em qual estrutura de integração se encontra o arquipélago Malvinas; 3) Efeitos do Brexit no arquipélago Malvinas.

Os procedimentos metodológicos foram baseados na análise de fontes primárias retiradas do sítio na rede mundial de computadores referentes ao Sistema de Comércio Internacional da CEPAL, bem como do anuário econômico do governo do arquipélago que formam o arcabouço da problemática e no exame de literatura e publicações especializadas.

Preocupa-se o presente artigo a reconhecer a repercussão econômica ofertada pela União Europeia aos britânicos e aplicada ao arquipélago Malvinas consagradas pelo Tratado de Lisboa de 2007 que amplia a possessões além-mar a chancela europeia para liberdade tarifária ao comércio, pois este foi um pedido requerido pelo Reino Unido na Cumbre de Lisboa, com intuito de permitir aos produtos dos territórios ultramarinos o acesso de seus produtos ao mercado da UE, porém, com o evento do Brexit, que, ocorrido em 31 de janeiro de 2020 deixa os ilhéus segundo Alencastro (2019) em situação instável, pois a perda do acesso privilegiado ao mercado europeu que, ao precisar recolher tributos, perderá competitividade e, consequentemente mercado consumidor. 
Após o conflito de 1982 e a partir deste evento, o Reino Unido intensifica a política na região, buscando majorar o fluxo comercial, pela via de déficits crescentes, bem como o investimento de caráter militar que se constitui na tomada de decisões dos habitantes locais e refletem diretamente na questão da identidade com a América Latina.

\section{CONTEXTUALIZAÇÃO}

A disposição britânica em manter bases em pontos estratégicos pelo globo advém da adoção de política expansionista oriunda das consequências da Revolução Industrial que possibilitou a expansão do comércio pela produção crescente de bens de consumo e da necessidade de angariar mercados consumidores. Referidas bases serviriam também para atestar o controle das rotas marítimas no mar, com a obtenção do domínio das linhas de comunicação entre os continentes para assegurar o livre transito dos negócios com as demais localidades do globo.

Desta feita, o crescimento da produção britânica além de exigir mercados consumidores também requer o acesso a fontes seguras de matérias-primas, através da conquista de territórios além-mar visando a continuidade da produção e consolidar posições para escoar o excedente da produção inglesa. Para Lanus (2016) a região austral do continente americano e, em especial, o arquipélago Malvinas não apresentava vantagens econômicas aos britânicos pela singularidade do território avesso a obtenção de matérias-primas e, em época remota, não era de conhecimento das autoridades o potencial de exploração econômica no mar.

\footnotetext{
"As Malvinas, que são atualmente uma estação naval de primeira ordem, construída especialmente para a defesa dos interesses britânicos na América do Sul, segundo os termos textuais da Conferência Naval de Cingapura, realizada em 1932. As Malvinas no sul. (...) A América Hispânica é livre, e se nós assentarmos firmemente nossos negócios, ela será inglesa, she is English" (Ortiz, 2014, p. 73).
}

Para Koutoudjian (2015), o Reino Unido enxerga na América Latina a oportunidade para obter alimentos, uma vez que seu território é escasso em terra e, portanto, pobre em ofertar segurança alimentar a sua população. Desta feita, o investimento no auge da revolução industrial, no século XIX em constituir a maior frota de navios de marinha mercante que exige a capacitação para a marinha de guerra através do controle de pontos cruciais através do globo. 
Estrategicamente, o Reino Unido já não possui mais o "status" de possuir a frota naval poderosa do globo, o que Ihe permitiu no passado estabelecer uma rede de possessões ultramar, porém remanesce com entraves que permanecem sob a tutela da coroa britânica como o arquipélago Malvinas (Bilmes, 2020). O fato de ainda pertencer a organismos internacionais como a OTAN (Organização do Tratado do Atlântico Norte) que estabelece aliança militar deve ser compreendido como motivo de preocupação para as pretensões argentinas na região.

Para Koutoudjian (2015) o motivo estratégico de controle dos mares que possibilitem o controle do tráfego marítimo no sul do continente americano passando pelo arquipélago Malvinas que Bilmes (2020) ressalta a necessidade da permanência da colonização britânica cujo aporto estratégico é essencial devido o encontro dos Oceanos Atlântico e Pacífico, que justifica a projeção de poder sobre terra no continente antártico (Vieira, 2006; Koutoudjian, 2015; Bilmes, 2020). Para isso, Vieira (2006) afirma que o envio de expedições científicas britânicas na região vem desde o século XIX, por isso a importância da presença física no arquipélago é essencial para justificar eventuais reivindicações territoriais no continente gelado e, assim, explorar as riquezas da região que leva HMG (2015) a investir $£ 300$ milhões no período entre 20152024 com intuito de dissuadir questionamentos sobre o domínio na região.

Argentina (2014) e Oliva (2013) ressaltam que todos os países da região se posicionam concretamente a favor do governo de Buenos Aires no que concerne aos direitos de pleitear a soberania no arquipélago Malvinas, bem como organismos internacionais apontam a necessidade do retorno a negociações bilaterais como a Organização das Nações Unidas (ONU), Organização dos Estados Americanos (OEA), Zona de Paz e Cooperação do Atlântico Sul (ZOPACAS), Sistema de Integración Centroamericano (SICA), o Grupo dos 77 mais a China e a Cúpula América do Sul - Países Árabes (ASPA).

O apoio de países vizinhos, bem como de Rússia e China que, segundo Oliva (2013) mostram reflexos da geopolítica atual que se redesenha com a ascensão de novas forças no tabuleiro global que apoiam as pretensões argentinas, porém ressalta a importância de estabelecer apoio firme das nações latino-americanas em foros 
regionais (Carvalho, 2016). Junto ao direcionamento argentino, os países vizinhos vão ao encontro da política de Buenos Aires, conforme ressalta Oliva (2013) no sentido de unir esforços contra forças externas no arquipélago e, acrescenta Carvalho (2016) a decisão de bloqueio nos portos do continente a navios de bandeira do arquipélago.

No caso específico do Brasil, a posição "da soberania argentina aplicou-se exclusivamente ao arquipélago Malvinas, e não às ilhas Geórgias do Sul e Sandwich do Sul" (Santos, 2016, p. 222) ampliado em 2010 e ratificado em 2019 por ocasião da visita do presidente Bolsonaro a Buenos Aires que inclui os "legítimos direitos da República Argentina na disputa de soberania com o Reino Unido da Grã-Bretanha e Irlanda do Norte, relativa às Ilhas Malvinas, Geórgias do Sul e Sandwich do Sul e aos espaços marítimos circundantes" (Brasil, 2019).

HMG (2012) indica que a política aplicada nos territórios além-mar, no caso específico do arquipélago Malvinas, exclui a possibilidade da participação de países da América Latina em processos de integração, pois estes estão reservados ao Reino Unido e ao seu "ethos" britânico de valores a serem multiplicados aos residentes locais, corroborando com Gamba e Smanio (2016) que acrescentam ser fundamental o estabelecimento de estruturas de cooperação entre os países para o sucesso de processo integracionistas, vedado pelos britânicos em relação a América Latina com o arquipélago.

Por isso, a apresentação de dados da CEPAL sobre a balança comercial do arquipélago Malvinas avalia-se, sob o ponto de vista do intercâmbio comercial, o entrave com os demais países da América Latina, visto que as relações comerciais impulsionaram compromissos e responsabilidades que aproximam nações e, por consequência, facilita o processo de integração com quem mantém vínculos mercantis, no caso em tela, o Reino Unido.

Nesse contexto, denota-se que os interesses exarados pelo Reino Unido no arquipélago Malvinas advém de décadas e o presente artigo fixa o recorte temporal limitado ao período compreendido entre o evento da Guerra das Malvinas (1982) até a publicação do último anuário disponibilizado na rede mundial de computadores do Sistema Gráfico de Comércio Internacional da CEPAL com dados referentes até 2018 e a 
descrição de cenários para os efeitos da saída do Reino Unido da União Europeia, processo que ficou conhecido pela sigla Brexit (Britain exit).

\section{AUSÊNCIA DE PARCERIAS COM PAÍSES DA AMÉRICA LATINA}

Neste item serão analisadas as relações comerciais do arquipélago Malvinas datadas do período compreendido entre 1982-2018 em sua balança comercial com dados oriundos da CEPAL e com quais países há maior assiduidade e continuidade no intercâmbio de produtos que visa a importação e exportação de um determinado país ou região.

A amostra utilizada sistematiza dados de 36 (trinta e seis) anos se fará de forma trienal com intuito de verificar com quais países o arquipélago Malvinas mantém relações comerciais, sendo que serão apresentados o rol com os principais parceiros e seu fluxo e, para efeitos didáticos elenca-se os 3 (três) maiores importadores e exportadores a ser analisado e seu cruzamento de dados. Desta forma, englobam-se as maiores diferenças na balança comercial na qual se verifica os efeitos do reflexo da estrutura de integração na qual a região estava inserida, após a adoção do Tratado de Lisboa.

Os dados a serem apresentados foram escolhidos da seguinte forma: inicia-se a série no ano de 1980 (antes do conflito), passando pelo ano de 1982 e o ano de 1983 (posterior ao conflito) e depois segue-se a sistemática trienal, exceção feita ao ano de 1990, onde reinicia-se nova contagem trienal.

Para Miyamoto (2009) a integração na América Latina sofre por não possuir estruturas sólidas, sendo conduzidas por dirigentes que aplicam políticas personalistas, apesar de sempre estar presente no discurso dos líderes políticos da região. A ocorrência de integração pressupõe a existência de comércio entre os países, pois, "o comércio inter-regional passa a exercer maior influência sobre o nível de atividade econômica e sobre a própria estrutura produtiva dos países" (Braga e Gremauld 2012, p.53).

Neste sentido, alerta Furtado (2007) que a integração dos países da América Latina perpassa pelo estigma do subdesenvolvimento, dado o manejo dos recursos naturais e da mão-de-obra, o que transformou as nações em concorrentes entre si, sem criação de 
vínculos comerciais, visando fornecimento de insumos às potências europeias; este panorama altera-se com os efeitos da crise de 1929 e do fim da Segunda Guerra Mundial (1939-1945) na qual há consciência entre os países latino-americanos, que vão iniciar processos de integração regional, em resposta a hegemonia dos Estados Unidos da América no continente. Neste debate ao qual se insere o arquipélago Malvinas, que apesar de ter o controle britânico, tem a chancela norte-americana que corrobora com o interesse de Londres.

Assim, partindo do princípio em que o Reino Unido utiliza-se de estruturas de integração estranhas à América Latina no arquipélago Malvinas verifica-se movimentação econômica influenciada pelos britânicos que asseguram também com investimentos militares na região (HMG, 2012 e HMG, 2015), com vistas a proporcionar segurança à população local, formada principalmente por militares britânicos e, desta forma, contaminam qualquer tentativa de solução final na questão da soberania do arquipélago.

Justifica-se a escolha dos dados da CEPAL por ser o órgão uma das cinco comissões ligadas à Organização das Nações Unidas e que desenvolve perspectivas econômicas sobre à América Latina, bem como proporcionar visibilidade frente a tentativa de dominação norte-americana (Furtado, 2007), acrescido a esta análise do documento do governo do arquipélago que exara a dependência do Reino Unido no tocante ao comércio de sua pauta exportadora.

As análises dos dados são feitas em três eixos a serem discutidos: 1) a manutenção paulatina do Reino Unido como importador de produtos do arquipélago Malvinas; 2) a ausência de países da América Latina como principais parceiros do arquipélago; 3) o impacto dos efeitos do Brexit nas relações comerciais do arquipélago.

Em primeiro lugar, é importante salientar que no tocante ao Reino Unido depreende-se que no ano de 1980 a balança comercial em relação ao arquipélago the era favorável no montante de US\$ 2,87 milhões, fato que se repete nos anos de 1986 com superávit de US\$2,53 milhões e no ano de 1999 com saldo positivo de US\$10,10 milhões. Nos demais anos analisados, o Reino Unido teve balança comercial desfavorável com o arquipélago e que se apresenta de maneira crescente, iniciando-se 
em 1982 com a cifra de US\$ 2,71 milhões e chegando ao ápice em 2014 (dentro da série analisada) ao montante de US\$110,66 milhões, ou seja, com aumento de quase $4.000 \%$ (quatro mil por cento) durante o período compreendido de 32 (trinta e dois) anos.

Desta forma, segundo pensamentos de Miyamoto (2009) e Vieira (2006) complementam-se uma vez que a estrutura imposta pelo Reino Unido vai permitir o crescimento de intercâmbio comercial em detrimento da ausência de países da América Latina que se intensifica após a adoção do Tratado de Lisboa, mas tendo em vista a preocupação exarada por State (2019) que enxerga a possibilidade de negócios com países da América Latina, em especial o Brasil.

\section{Gráfico 1 - Saldo da Balança Comercial do Reino Unido e do Arquipélago Malvinas}

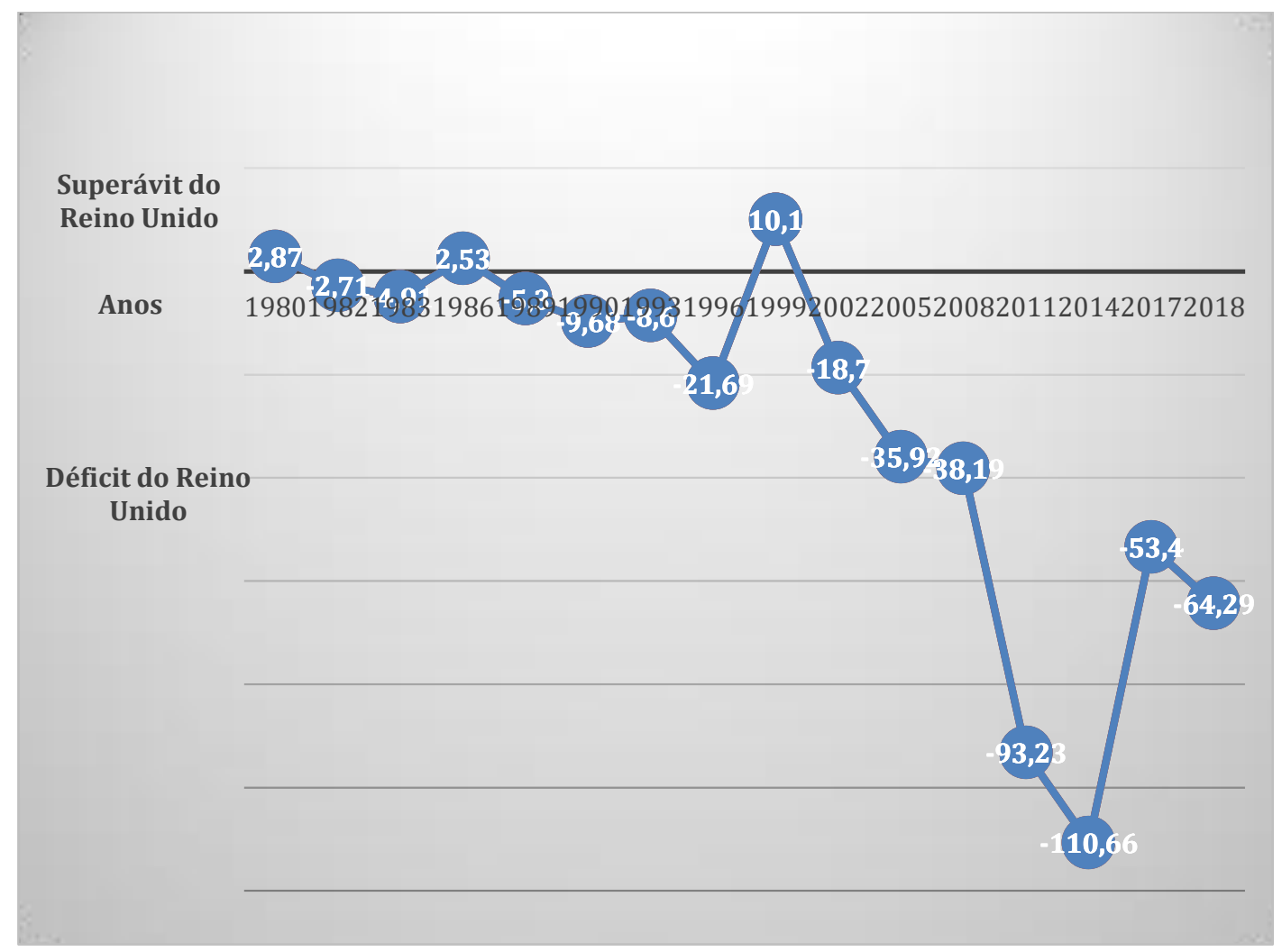

Fonte: Adaptação do autor em relação aos dados do sistema internacional de comércio da CEPAL (CEPAL, 2019).

Além da balança comercial desfavorável, o Reino Unido também faz aportes no campo militar, uma vez que os documentos de estratégia e defesa britânicos em seus territórios além-mar e devido ao advento do conflito armado em 1982, o arquipélago que não estava no rol das maiores preocupações do "Foreign Office" ganha destaque e consequentemente maiores inversões pelos britânicos nos anos seguintes, uma vez que 
entenderam que a defesa do território é importante para a manutenção de suas pretensões no entorno estratégico do arquipélago (HMG, 2015 e HMG, 2012).

Os habitantes das ilhas não buscam parceiros, tendo em vista que o Reino Unido Ihes garante boa fatia de compra de produtos destinados à exportação, além de gerir sua defesa e segurança contra invasores externos. Isto justifica, por exemplo, o comparecimento no plebiscito de 2013 na qual a opção pelo sentimento britânico vem como forma de retribuição ao investimento e confiança depositada pela tomada de decisões de Londres, mas que poderá mudar com o que vier a ocorrer em relação ao Brexit.

Tabela 1 - Indicadores de comércio de exportação e importação do arquipélago Malvinas segundo dados do Sistema de Comércio Internacional da CEPAL (1980-1996).

\begin{tabular}{|c|c|c|c|c|}
\hline \multirow{2}{*}{ Ano } & \multicolumn{2}{|c|}{ Exportações } & \multicolumn{2}{|c|}{ Importações } \\
\hline & País & US\$/mihões & País & US\$/milhões \\
\hline \multirow{3}{*}{1980} & GBR & 2,87 & ITA & 0,47 \\
\hline & FRA & 1,18 & BEL-LUX & 0,22 \\
\hline & JPN & 0,44 & IND & 0,05 \\
\hline \multirow{3}{*}{1982} & JPN & 0,55 & GBR & 2,71 \\
\hline & PAK & 0,19 & SWE & 2,2 \\
\hline & FRA & 0,06 & ESP & 0,41 \\
\hline \multirow{3}{*}{1983} & JPN & 0,8 & SWE & 19,69 \\
\hline & FRA & 0,32 & GBR & 4,91 \\
\hline & NLD & 0,22 & ITA & 0,95 \\
\hline \multirow{3}{*}{1986} & GBR & 2,53 & USA & 1,38 \\
\hline & FRA & 1,18 & ITA & 0,35 \\
\hline & ESP & 0,72 & DNK & 0,21 \\
\hline \multirow{3}{*}{1989} & GER & 2,14 & GBR & 5,3 \\
\hline & NOR & 1,18 & ITA & 2,24 \\
\hline & ISL & 0,92 & SWE & 1,21 \\
\hline \multirow{3}{*}{1990} & USA & 1,35 & GBR & 9,68 \\
\hline & NLD & 0,2 & ITA & 8,07 \\
\hline & YUG & 0,2 & PAK & 0,59 \\
\hline \multirow{3}{*}{1993} & ISL & 0,66 & GBR & 8,6 \\
\hline & NLD & 0,51 & ITA & 2,83 \\
\hline & POR & 0,44 & GER & 0,24 \\
\hline \multirow{3}{*}{1996} & ESP & 32,33 & GBR & 21,69 \\
\hline & FRO & 0,48 & POR & 11,81 \\
\hline & NOR & 0,57 & ITA & 3,48 \\
\hline
\end{tabular}


Fonte: Elaboração própria. Adaptação do autor em relação aos dados do sistema internacional de comércio da CEPAL (CEPAL, 2019).

Por outro lado, enquanto o Reino Unido encontra-se em posição privilegiada com o arquipélago Malvinas, a análise dos dados pesquisados verifica-se a presença pífia de países da América Latina. Dentre o período retromencionado, citam-se os anos de 1993, 1999 e 2008, onde aparece a Costa Rica em posição marginal e com balança estável, bem como Honduras no ano de 2002 com o mesmo percentual. Economias como México e Brasil não apresentam superávits ou déficits de grande envergadura, sendo que no caso mexicano o ano de 2005 teve superávit de US\$ 0,09 milhões, nos anos de 2011, 2014 e 2018 saldo neutro e 2017 com superávit de US\$ 0,04 milhões. Com o Brasil, nota-se a presença no ano de 2005 e 2014 com saldo neutro, em 2008 com superávit de US\$ 0,03 milhões e, em 2011, déficit de US\$ 0,04 milhões. Cita-se, ainda, o Peru que no ano de 2008 teve superávit de US\$ 0,02 milhões na balança comercial, o Paraguai que em 2011 teve superávit de US\$ 0,12 milhões e o Equador que no mesmo ano apresentou saldo neutro no tocante a balança comercial com o arquipélago. 
Tabela 2 - Indicadores de comércio de exportação e importação do arquipélago Malvinas segundo dados do Sistema de Comércio Internacional da CEPAL (1999-2018)

\begin{tabular}{|c|c|c|c|c|}
\hline \multirow{2}{*}{ Ano } & \multicolumn{2}{|c|}{ Exportação } & \multicolumn{2}{|c|}{ Importações } \\
\hline & País & US\$/milhões & País & US\$/milhões \\
\hline \multirow{3}{*}{1999} & ESP & 59,09 & ITA & 4,85 \\
\hline & GBR & 10,1 & NLD & 1,29 \\
\hline & GER & 4,01 & POR & 0,48 \\
\hline \multirow{3}{*}{2002} & ESP & 57,97 & GBR & 18,7 \\
\hline & USA & 5,81 & ITA & 7,35 \\
\hline & CZE & 3,33 & IND & 0,17 \\
\hline \multirow{3}{*}{2005} & ESP & 131,97 & NLD & 277,4 \\
\hline & CRO & 8,55 & GBR & 35,92 \\
\hline & CZE & 2,35 & AUS & 0,51 \\
\hline \multirow{3}{*}{2008} & ESP & 124,17 & GBR & 38,19 \\
\hline & DNK & 17,69 & GRE & 15,46 \\
\hline & $\mathrm{HRU}$ & 9,8 & LAT & 0,43 \\
\hline \multirow{3}{*}{2011} & ESP & 142,11 & GBR & 93,23 \\
\hline & HRV & 7,64 & NLD & 55,66 \\
\hline & CZE & 3,71 & GRE & 24,2 \\
\hline \multirow{3}{*}{2014} & ESP & 137,87 & GBR & 110,66 \\
\hline & USA & 12,07 & GRE & 40,55 \\
\hline & NAM & 7,99 & RUS & 8,56 \\
\hline \multirow{3}{*}{2017} & ESP & 137 & GBR & 53,4 \\
\hline & USA & 11,34 & GRE & 12,89 \\
\hline & NAM & 6,97 & NDL & 6,49 \\
\hline \multirow{3}{*}{2018} & USA & 12,96 & GBR & 64,74 \\
\hline & GBR & 5,44 & GRE & 7,74 \\
\hline & GER & 4,18 & RUS & 0,99 \\
\hline
\end{tabular}

Fonte: Elaboração própria. Adaptação do autor em relação aos dados do sistema internacional de comércio da CEPAL (Cepal, 2019).

Por fim, denota-se que os britânicos possuem sucessivos e crescentes déficits na balança comercial com o arquipélago Malvinas que coincidem com a aplicação de política de aproximação com o território além-mar que tem recebido montante financeiro do Reino Unido, ou seja, denota-se que há duas formas de entrada de dinheiro no arquipélago dados pelos investimentos diretos e das importações.

Estes elementos acima integrados reverberam a importância da atuação do Reino Unido para a atual conjuntura econômica do arquipélago Malvinas. A estrutura 
econômica, ao direcionar somas cada vez maiores à região causa solidificação do pensamento mais próximo ao britânico e, consequentemente, mais longínquo da integração com a América Latina, contrariamente ao pensamento defendido por Pereira (2016) e Miyamoto (2009).

O Reino Unido no momento em que abriga a defesa dos interesses de cidadãos britânicos e dos territórios além-mar esconde prioridades que os mantém na região (Coggiola, 2014), notadamente por acesso a rotas e riquezas marítimas e a exploração futura do continente antártico, pois "o continente antecipou disputas entre Argentina e Grã-Bretanha sobre partes do território continental, com a destruição de instalações e a captura de embarcações de um país por outro" (Vieira, 2006, p.53), bem como manter bases militares avançadas que servem aos interesses dos Estados Unidos da América e da Organização do Tratado do Atlântico Norte em detrimento do avanço chinês que já se encontra solidificado na África e em expansão na América Latina.

Portanto, a ausência de fluxo comercial com países da América Latina se deve ao fato de que a inserção do arquipélago estava atrelada a integração com a UE, dado a sua situação jurídica de território ultramarino britânico e considerado europeu (Alencastro, 2019), mas que não possui autonomia em assuntos de defesa e nos negócios estrangeiros, o que indica segundo Lanus (2016) a manutenção do status de colônia britânica o arquipélago Malvinas, dando-Ihe nova roupagem, tendo em vista a concessão de direitos pontuais aos ilhéus, em oposição ao que defende o governo britânico das ilhas que rechaça o termo colônia à sua situação jurídica. Erlich (2020) defende a ideia na qual o colonialismo britânico na região persiste desde o século XIX com o desembarque de cidadãos ingleses com o objetivo de mantê-los e, assim, justificar a posse do arquipélago.

\section{EFEITOS DO BREXIT NO ARQUIPÉLAGO MALVINAS}

A saída do Reino Unido da União Europeia impacta o destino de produtos do arquipélago que perde o acesso privilegiado ao bloco europeu. A questão apresentada por Bilmes (2020) debate se este fato representa uma oportunidade ou ameaça à Argentina em suas pretensões. Alencastro (2019) pontua que o Brexit pode redefinir a 
geopolítica do Atlântico Sul. Em escala global, Tokatlian (2020) acena que este processo pode acelerar a perda de divisas e influência no concerto de nações.

Baer (2017) externa a preocupação do comércio com a Espanha conforme números apresentados na Tabela 2 que mostra a proeminência da balança comercial favorável ao arquipélago de maneira considerável, bem como Ablin (2016) sustenta a possibilidade de oportunidade de abertura com os países da América Latina de se aproximar do arquipélago a partir do momento da saída britânica do seio das nações da UE, no mesmo sentido Lucotti (2020) afirma que os ilhéus estão em situação de vulnerabilidade, devido a perda de vantagens que possuíam quando o Reino Unido era integrante do bloco europeu.

A título de exemplo, ao verificar a tabela adaptada pelos dados da CEPAL que mostra os países com os quais o arquipélago possui maiores transações, percebe-se a intensidade da presença de países do bloco da União Europeia, no período analisado, principalmente pela aplicação das benesses do fluxo mercantil permitidas pelas diretrizes da integração, quando o Reino Unido pertencia ao bloco.

No cruzamento de dados entre as Tabelas 1 e Tabela 2, denota-se o déficit em desfavor dos britânicos, o que indica a transferência velada de renda de Londres ao arquipélago, o que contribui para o reforço do sentimento da população pela britanicidade que é objeto dos documentos de segurança e defesa britânicos (HMG, 2015) e repúdio a integração com a América Latina.

Hodiernamente, os números ainda das Tabelas 1 e 2, bem como a Tabela 3 corroboram com o exposto no documento intitulado "The Overseas Territories" (HMG, 2012), na qual a necessidade dos britânicos patrocinar a defesa e segurança destes territórios, projetando-Ihes assistência econômica, suporte técnico nas relações internacionais, bem como a outorga de benefícios em troca de produtos que sejam relevantes para a sua economia doméstica, no caso em tela, notadamente o acesso e exploração de petróleo e gás, além de sua privilegiada posição estratégica ímpar no Atlântico Sul.

Coggiola (2014) aduz no tocante as rendas produzidas pelo arquipélago Malvinas gerou acréscimo no nível de renda dos habitantes das ilhas, tornando superior a média 
de qualquer outro país latino-americano, pois o aporte da tributação petroleira "baseada em $9 \%$ do faturamento e $26 \%$ dos lucros das companhias inglesas já instaladas no arquipélago" (Coggiola 2014, p. 187) permite o fortalecimento de laços com o Reino Unido.

Segundo dados apresentados em tabela anexada a este trabalho a importação de produtos é oriunda de países da União Europeia, liderados pelo Reino Unido. Isto também impacta na mão-de-obra, pois segundo State (2019) a necessidade de profissionais nas áreas de engenharia, transporte e construção, saúde e ligados às atividades primárias petroleiras e de pesca é crescente devido aos resultados favoráveis da economia local que alia baixo índice de desemprego e necessidade de investimento em geração de riquezas.

Tabela 3 - Indicadores econômicos da pauta de exportação do arquipélago Malvinas do ano de 2017, segundo dados de State (2019).

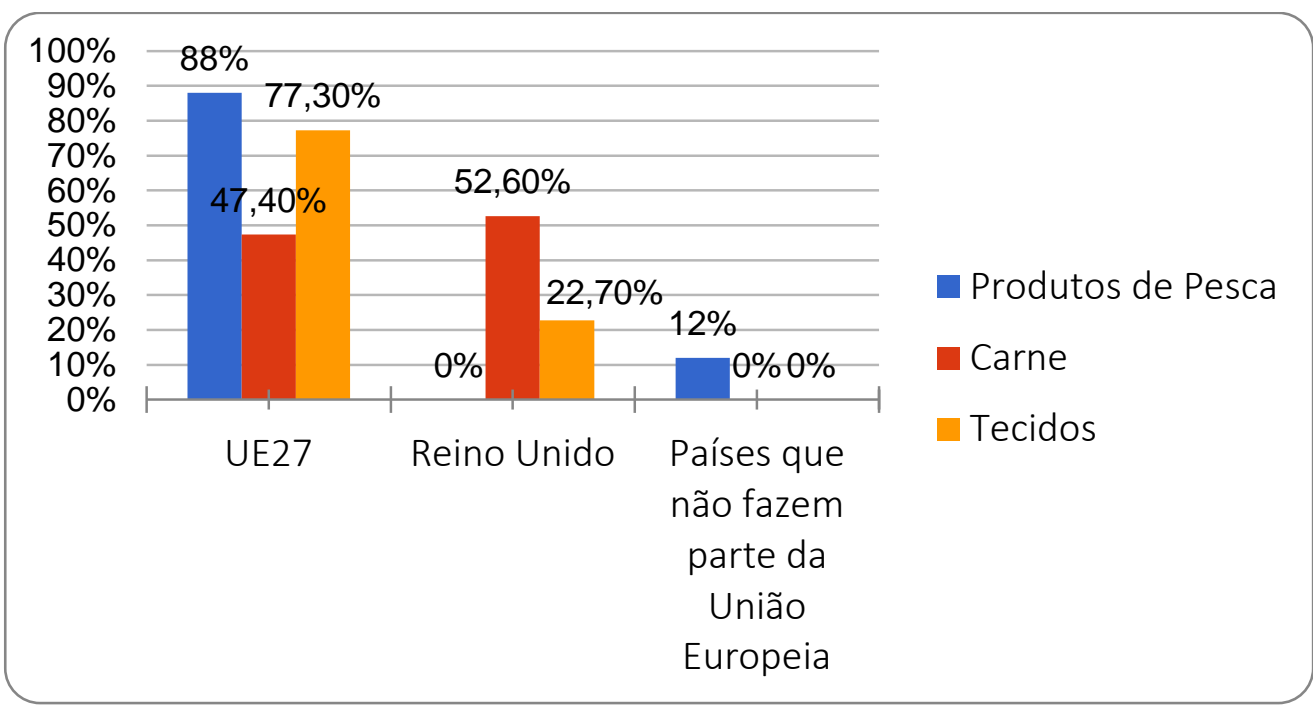

Fonte: Elaboração própria. Adaptação do autor em relação aos dados de State (2019).

No entanto, a postura das autoridades do arquipélago, ao destacar os efeitos do Brexit sobre sua economia, alerta para o decréscimo de parceiros tradicionais como Espanha, Reino Unido e Estados Unidos da América e começa a enxergar a América Latina como possível destino a iniciar tratativas de aproximação e, com relação ao Brasil, alerta para o risco do processo de recessão econômica, iniciado em 2015 e que pode se manter, bem como a expectativa da inauguração de voo comercial semanal 
regular entre São Paulo (GRU) e o arquipélago, trazendo "benefícios de sociabilidade e qualidade de vida" (State, 2019, p.24).

Limia (2020) adverte que o cenário do Brexit agora concretizado trará repercussões negativas em curto prazo, com reduções comerciais significativas, o que pode segundo o autor dar viabilidade entre a Argentina e a União Europeia que poderá converter o apoio do bloco favoravelmente à Buenos Aires, desde que isso seja trabalhado no médio e longo prazo, pois há questões internas de outros países da UE com os britânicos que poderá voltar a aflorar e, assim, se unir aos argentinos em seu pleito.

Com isso, a política argentina reforça a necessidade de estabelecer política de Estado sobre a pretensão de soberania no arquipélago que nas palavras de Lucotti (2020) estão preconizadas em três ações: a) criar conselho nacional representado por intelectuais, políticos e militares sem vinculação com o governo, buscando independência junto ao mesmo; b) demarcar a ampliação da plataforma continental argentina já outorgada pelas Nações Unidas e; c) alterar o regime federal de pesca com intuito de coibir trânsito ilegal em embarcações que retirem recursos marinhos cuja jurisdição é argentina.

\section{CONSIDERAÇÕES FINAIS}

O Reino Unido, ao consolidar o domínio no arquipélago Malvinas busca transmitir a imagem de potência na região e, com isso, atrapalhar as intenções de integrar a região à América Latina. A posição britânica de dominação sobre a região é demonstrada pela forte presença na balança comercial com os produtos provenientes do arquipélago, bem como a manutenção da estrutura vinculada a União Europeia visualiza-se nas relações comerciais com quem o arquipélago mantém, excluindo-se praticamente a fronteira com os países latino-americanos.

O empoderamento da presente discussão se faz presente através da junção de dados da CEPAL, bem como de doutrinadores e documentos oficiais do governo britânico e do arquipélago, que apresentam nuances diferentes no debate da presente questão. Denota-se que o governo britânico mostra-se disposto a investir econômica e militarmente na região por questões estratégicas, enquanto o arquipélago mostra-se preocupado em sua balança comercial. 
Todavia, as tabelas e gráficos apresentados no presente trabalho tem o viés de confirmar a hipótese na qual o comércio do arquipélago está fortemente integrado com o Reino Unido e com países da União Europeia, pois a pauta de exportações vincula-se ao grupo de países na qual a comercialização ocorre de maneira benéfica, com acesso livre de tarifas de acordo com as regras de estrutura de integração regional com o qual os britânicos inseriram pelas regras do Tratado de Lisboa.

Mesmo com o recorte feito pelo pesquisador, denota-se que majoritariamente os países que mantém maiores déficits com o arquipélago eram oriundos de países da União Europeia, o que significa dizer que o arquipélago mantinha vantagens em abrigarse sob o guarda chuva europeu, patrocinado pelo Reino Unido, o que justificou o acachapante resultado do referendo de 2013. Porém, com o Brexit, novos cenários serão construídos, bem como as relações dos países latino-americanos com 0 arquipélago, com a perspectiva de incremento nas relações econômicas, políticas e sociais.

Hodiernamente, o Reino Unido, se mantém no arquipélago para controlar as rotas de navegação do sul do continente, explorar as riquezas do entorno das ilhas e, ainda, justificar eventuais reivindicações futuras no continente antártico e estes elementos em conjunto justificam as inversões dos cofres britânicos seja na injeção de dinheiro na economia ou ainda com viés militar.

A visibilidade para a presente questão é importante diante das mudanças e da reconfiguração de poder no globo. Apesar de longínquo, a importância do arquipélago é fundamental para a América Latina, por isso o apoio das nações indica o amadurecimento institucional que deve ser levado adiante no intuito de encontrar solução harmoniosa para o feito. Entretanto, o evento do Brexit ainda é recente e ainda há negociações entre as partes cujo reflexo depende de analisar as conjunturas do acordo, mesmo cientes que há a sinalização de diminuição de exportações na economia do arquipélago e abre-se oportunidade para a Argentina avançar com seus protestos em foros internacionais, apoiadas pelos vizinhos. Trata-se de processo em andamento e, portanto, haverá movimentos diplomáticos cujas decisões impactarão a demanda aqui exposta. 
De melhor sorte, as ações delineadas pela Argentina são compreendidas pelos países vizinhos e outros do globo (como China e Rússia) ao demonstrar o apoio que detém no embate pela disputa de soberania com o Reino Unido que ganha destaque em foros internacionais e encontros bilaterais proporcionando maior visibilidade para o conhecimento da questão Malvinas e sua difícil resolução.

A maior lição deste episódio é a necessidade da união das nações latino-americanas em torno de causa comum que afeta a todos e que precisa de coordenação e paciência na luta para obter resultados favoráveis no horizonte futuro. As perspectivas indicadas pelos autores utilizados neste trabalho indicam a abertura de oportunidade em imprimir maiores esforços diplomáticos na busca de solucionar definitivamente a presente questão de soberania do arquipélago Malvinas.

Apesar da dificuldade metodológica de encontrar material disponível em artigos científicos e livros acadêmicos que tratem de temática multidisciplinar, com foco na parte econômica também envolve ditames políticos e militares e que possui repercussão em eventos futuros que impactarão o futuro do destino do continente gelado, bem como de novos reposicionamentos da pauta de exportação que podem abrir oportunidade de realizar a comercialização com os países latino-americanos.

\section{REFERÊNCIAS}

Ablin, E. R. (2016). Eventuales efectos del "brexit" sobre las Islas Malvinas: Cambia algo? Centro de estudios de política internacional. Buenos Aires.

Alencastro, L. F. (2019). O Brexit, as Malvinas e o Atlântico Sul. Disponível em: $<$ https://noticias.uol.com.br/blogs-e-colunas/coluna/luiz-felipe-

alencastro/2019/10/22/o-brexit-as-malvinas-e-o-atlantico-sul.htm>. [Acesso em: 25 abr. 2020].

Argentina. (2014). La comunidad internacional y la cuestión Malvinas. Buenos Aires: República Argentina.

Baer, J. (2017). Brexit Implications for Falkland/Malvinas Dispute. Disponível em: <http://www.coha.org/wp-content/uploads/2017/02/brexitbaer.pdf>. [Acesso em: 04 mai. 2019].

Bilmes, J. (2020). Malvinas después del Brexit: nuevos escenarios ante la profundización de la crisis mundial. Disponível em: <https://cronistaslatinoamericanos.com/malvinasdespues-del-brexit-nuevos-escenarios-ante-la-profundizacion-de-la-crisis-mundial/>. [Acesso em: 25 abr. 2020]. 
Braga, M. B.; Gremaud, A. P. (2012). 'Cooperação macroeconômica na América Latina: possibilidade ou utopia?', Carta Internacional (USP), v. 7, p. 50-65.

Brasil. (2019). Ministério de Relações Exteriores, 'Declaração Conjunta Presidencial por ocasião da visita de Estado do Presidente Jair Bolsonaro a Buenos Aires', Nota 151, 06 de junho. Disponível em: <http://www.itamaraty.gov.br/pt-BR/notas-aimprensa/20484-declaracao-conjunta-presidencial-por-ocasiao-da-visita-de-estado-dopresidente-jair-bolsonaro-a-buenos-aires>. [Acesso em: 25 abr. 2020].

Carvalho, R. N. (2016). Ilhas malvinas: Análise de segurança e defesa no atlântico sul. Anais do II Simpósio Internacional Pensar e Repensar a América Latina. Disponível em: <https://sites.usp.br/prolam/wp-content/uploads/sites/35/2016/12/CARVALHO_SP04Anais-do-II-Simp\%C3\%B3sio-Internacional-Pensar-e-Repensar-a-Am\%C3\%A9ricaLatina.pdf>. [Acesso em: 19 mai. 2020].

CEPAL. (2019). SIGCl - 'Sistema Gráfico de Comércio Internacional'. Santiago do Chile.

Coggiola, O. (2014). A outra guerra do fim do mundo: A Batalha pelas Malvinas e a América do Sul. Cotia: Ateliê Editorial.

Erlich, U. (2020). "Malvinas, soberania e integración regional", in: Malvinas, una causa regional justa. Cuidad Autónoma de Buenos Aires: CLACSO, p. 91-102.

Furtado, C. (2007). A economia latino-americana. 4ạ. Ed. São Paulo: Companhia das Letras.

HMG - Her Majesty'S Government. (2015). A Secure and Prosperous United Kingdom. London: Her Majesty's Stationery Office.

(2012). The Overseas Territories: Security, Success and Sustainability. London: Her Majesty's Stationery Office.

Koutoudjian, A. (2015). "Geopolítica del Atlántico Sur", in: Geopolitica del Mar Argentino. Cuidad Autonóma de Buenos Aires: Instituto de Publicaciones Navales.

Lanus, J. A. (org.). (2016). Repensando Malvinas - una causa nacional. Buenos Aires: Editorial El Ateneo.

Limia, E. (2020). El brexit influirá en la economía de Las Malvinas y en la esperanza de Argentina sobre ellas. Disponível em: < https://www.aa.com.tr/es/econom\%C3\%ADa/elbrexit-influir\%C3\%A1-en-la-econom\%C3\%ADa-de-las-malvinas-y-en-la-esperanza-deargentina-sobre-ellas-/1740941>. [Acesso em: 25 abr. 2020].

Lucotti, F. (2020). Argentina redobla su reclamo por Malvinas con tres nuevas políticas de Estado. Disponível em: <https://mundo.sputniknews.com/americalatina/202003051090693184-argentina-redobla-su-reclamo-por-malvinas-con-tresnuevas-politicas-de-estado/>. [Acesso em: 25 abr. 2020].

Miyamoto, S. (2009). 'O Brasil e a América Latina: opções políticas e integração regional', Cadernos Prolam/USP, 8(1), p. 89-110. 
Oliva, E. (2013). Malvinas: el passado es el prólogo. 1ạ Ed. Buenos Aires: Fabro.

Ortiz, R. S. (2014). Política Britânica no Rio da Prata. Florianopólis: Insular.

Pastorino, A. (2013). Malvinas: el derecho de libre determinación de los pueblos y la población de las islas. 1a. Ed. Cuidad Autónoma de Buenos Aires: Eudeba.

Pereira, F. D. (2016). 'O lugar da América Latina nas relações sul-sul: o papel da comunidade de Estados latino-americanos e caribenhos (CELAC) na integração latinoamericana', Cadernos Prolam/USP, 15(29), p. 121-135, jul/dez.

Santos, E. (2016). Entre o Beagle e as Malvinas: conflito e diplomacia na América do Sul. Brasília: FUNAG.

State of the Falkland Islands Economy 2018. (2019). 'Falkland Islands Government'. Disponível em: <https://www.fig.gov.fk/policy/component/jdownloads/send/5-reportsand-publications/123-state-of-the-falkland-islands-economy-2018>.[ Acesso em: 15 mai. 2019].

Tokatlian, J. G. (2020). "Malvinas: consenso, calma y creatividad", in: Malvinas, una causa regional justa. Cuidad Autónoma de Buenos Aires: CLACSO, p. 75-84.

Vieira, F. B. (2006). 'O Tratado da Antártica: perspectivas territorialista e internacionalista', Cadernos Prolam/USP, 5(2), p. 49-82. 